\title{
Release of particles, organic compounds, and metals from crumb rubber used in synthetic turf under chemical and physical stress
}

\author{
Silvia Canepari ${ }^{1}$ (D) Paola Castellano ${ }^{2} \cdot$ Maria Luisa Astolfi $^{1} \cdot$ Stefano Materazzi $^{1}$. \\ Riccardo Ferrante ${ }^{3} \cdot$ Dennis Fiorini $^{4} \cdot$ Roberta Curini $^{1}$
}

Received: 5 July 2016 / Accepted: 2 October 2017

(C) Springer-Verlag GmbH Germany 2017

\begin{abstract}
The chemical and morphological characteristics of materials released under chemical and physical stress by different rubber granulates used as infill materials in synthetic turf (recycled scrap tires, natural rubber, and a newgeneration thermoplastic elastomer) were compared.

The headspace solid-phase micro-extraction GC-MS analysis evidenced that at $70{ }^{\circ} \mathrm{C}$ natural rubber and thermoplastic elastomer release amounts of organic species much higher than recycled scrap tires. In particular, the desorption of mineral oils, with a prevalence of toxicologically relevant lowviscosity alkanes in the range $\mathrm{C} 17-\mathrm{C} 22$, and plasticizers (diisobutyl phthalate) was clearly evidenced. The newgeneration thermoplastic elastomer material also releases butylated hydroxytoluene.

In slightly acidic conditions, quite high amounts of bioaccessible $\mathrm{Zn}, \mathrm{Cu}$, and $\mathrm{Co}$ are released from recycled scrap tires, while natural rubber releases mainly Se and Tl. In
\end{abstract}

Responsible editor: Roland Kallenborn

Electronic supplementary material The online version of this article (https://doi.org/10.1007/s11356-017-0377-4) contains supplementary material, which is available to authorized users.

Silvia Canepari

silvia.canepari@uniroma1.it

1 Chemistry Department, Sapienza University of Rome, P.le Aldo Moro, 5, 00185 Rome, Italy

2 Local Office of Aosta, INAIL-Italian Workers' Compensation Authority, Corso Padre Lorenzo, 18, 11100 Aosta, Italy

3 Department of Occupational Hygiene, INAIL-Italian Workers' Compensation Authority, Research Area, via Fontana Candida 1, 00040 Monteporzio Catone, Rome, Italy

4 Chemistry Division, School of Science and Technology, University of Camerino, V. S. Agostino 1, 62032 Camerino, MC, Italy contrast, the thermoplastic elastomer does not contain significant concentrations of leachable heavy metals.

The formation of small particles, also in the inhalable fraction, was evidenced by electron microscopy after mechanical or thermal treatment of natural rubber.

Keywords Synthetic turf $\cdot$ Crumb rubber $\cdot$ Semi-volatile organic compounds $\cdot$ Headspace solid-phase micro-extraction GC-MS · Bio-accessible fraction of elements · Inhalable particles

\section{Introduction}

Grass-like surfaces are extensively used for blanket lawns, park spaces, and athletic fields where children and adults relax and play, but a number of questions regarding their potential effects on health and environment are still largely unanswered (Birkholz et al. 2003; Whitlock 2008; EPA 2009; Simon 2010; Van Ulirsch et al. 2010; Ginsberg et al. 2011; Serensits et al. 2011; Ruffino et al. 2013; Cheng et al. 2014). The main sources of concern regard the use of rubber granulates as infill material (Claudio 2008; Zhang et al. 2008). All these materials contain many species that are added to rubber during its production, namely filler systems (carbon black, clays, silicas, calcium carbonate), stabilizer systems (antioxidants, antiozonants, waxes), cross-linking agents (sulfur, accelerators, activators), and secondary components such as pigments, oils, resins, and short fibers, potentially harmful for health and environment (Sadiktsis et al. 2012; Rodgers and Waddell 2013; Ruffino et al. 2013; Cheng et al. 2014).

The potential risks for health and environment from rubber granulates can arise from different mechanisms. Volatile compounds may be desorbed from the rubber ( $\mathrm{Li}$ et al. 2010; Simcox et al. 2011), especially during the summer, when the 
synthetic turf can reach temperatures up to about $70{ }^{\circ} \mathrm{C}$ (Claudio 2008). Furthermore, the bio-accessible species may be released to humans by dermal exposure and ingestion and may be transferred to the soil and surface water and/or ground water (Bocca et al. 2009; Cheng et al. 2014; Pavilonis et al. 2014). It should also be considered that in outdoor environments, rubbers are exposed to oxidizing agents, light, temperature, and rain; these conditions may reduce their mechanical resistance and enhance the release of toxic agents (Zhang et al. 2009; Cheng et al. 2014). Further studies should thus address the behavior of these materials under unfavorable conditions, also considering that children are the most affected population (Van Ulirsch et al. 2010; Ginsberg et al. 2011; Kim et al. 2012; Cheng et al. 2014).

During the past years, scrap tires or simply recycled rubbers have been the most frequently used materials (Zhang et al. 2008; Bocca et al. 2009; Wik and Dave 2009; Ruffino et al. 2013); these recycled materials also contain species retained by the rubber during its first life. Previous studies about the chemical composition of used tire rubber demonstrate that this recycled material contains relatively high amounts of polyaromatic hydrocarbons (PAHs), phthalates, volatile organic compounds (VOCs), and heavy metals, also in leachable forms (Smolders and Degryse 2002; Bocca et al. 2009; Kwon and Castaldi 2009, Zhang et al. 2009, Kreider et al. 2010; Li et al. 2010; Kim et al. 2012; Krüger et al. 2012; Llompart et al. 2013).

The main problem encountered in the field evaluation of the exposure risks is that synthetic turf is mainly used in open spaces, frequently located in urban environments. The specific emission from this source is then masked by the air pollution due to other sources; these sources, as in the case of tire abrasion from traffic, may produce very similar emissions (Canepari et al. 2008, 2010; Wik and Dave 2009; Kreider et al. 2010). Regarding indoor environments, some studies performed in sport facilities have evidenced the presence of very low concentrations of PAHs and VOCs, suggesting that the health risks are minimal (Van Rooij and Jongeneelen 2010); however, other studies performed in similar conditions report relatively high concentration of PAHs, benzothiazole, naphthalenes, and several VOCs measured in indoor sports facilities with artificial turf (Ginsberg et al. 2011; Simcox et al. 2011). Because of the controversial discussions on the scrap tires toxicity, natural rubber (NR) and other thermoplastic materials are now also frequently used, but their environmental behavior is largely unknown (Gomes et al. 2010).

In this study, we tried to evaluate the potential effects on health and environment of different crumb rubbers (recycled styrene-butadiene tire rubber (SBR), natural rubber (NR), and last-generation thermoplastic elastomer crumb (TPE)) by studying the thermal desorption of organic species and the leachable fraction of elements in the most unfavorable environmental conditions reached by these materials when used in the field. The possible re-suspension of inhalable particles was also checked by scanning electron microscope combined with energy-dispersive spectrometer (SEM-EDS) analysis of crumb rubbers before and after physical and chemical treatments.

\section{Experimental}

\section{Samples}

Different crumb rubber materials were considered in this study: SBR, NR, and TPE. In the case of NR, the study included two different fresh materials from sealed storage bags (NR1 and NR2) and a 7-year-aged sample (NR3 with composition 1:1 of NR1 and NR2). Where the kind of NR is not specified in the text, the results refer to NR3.

Due to the inhomogeneity of the rubber samples, some preliminary tests were performed to evaluate the minimum amount of crumb rubber materials that was necessary to analyze to ensure representative results. In these tests, variable amounts (ranging from $0.1 \mathrm{~g}$ to $1.0 \mathrm{~g}$, in increments of $0.1 \mathrm{~g}$ ) of each rubber material were weighted, subjected to microwave-assisted extraction (MAE, Milestone Ethos Touch Control with HPR 1000/6S rotor) in acetic acid $0.5 \mathrm{M}$, and analyzed by inductively coupled plasma-optical emission spectrometry (ICP-OES; Varian Vista MPX CCD Simultaneous ICP-OES, Mulgrave, Australia with ultrasonic nebulizer U $5000 \mathrm{AT}^{+}$, Cetac Technologies, Omaha, NE, USA) and by inductively coupled plasma-mass spectrometry (ICP-MS; Varian 810, Mulgrave, Australia). Further details about this procedure are given in the "Elemental analysis" section.

For each weighted amount, we calculated the standard deviation (SD) of the measured elemental concentration (six replicates). As the obtained SDs were affected by both the method's analytical repeatability (which is independent from the sample amount, at least when the measured concentrations are above the quantification limits) and the inhomogeneity of the sample, we considered the minimum sample amount allowing the achievement of a constant SD value. For all the materials, no improvements of the SD value were obtained by increasing the weighted amounts above $0.5 \mathrm{~g}$. All the successive tests, if not differently specified, were performed by extracting $0.5 \mathrm{~g}$ of crumb rubber.

\section{Thermogravimetric analysis}

The thermogravimetric analysis of the samples was aimed to the comparison among the releasing steps of each examined tire or rubber sample (Quek and Balasubramanian 2009; Kreider et al. 2010). 
The thermogravimetric analysis (TGA) profiles were obtained on 10 to $20-\mathrm{mg}$ samples by a Perkin Elmer 7Series TGA in air flow $(100 \mathrm{~mL} / \mathrm{min})$ and with the following scan rate program: heating rate of $10{ }^{\circ} \mathrm{C} / \mathrm{min}$ from 25 to $70{ }^{\circ} \mathrm{C}$, isothermal step of $20 \mathrm{~min}$ at $75^{\circ} \mathrm{C}$, heating rate of $10{ }^{\circ} \mathrm{C} /$ $\min$ from 75 to $150^{\circ} \mathrm{C}$.

\section{Headspace solid-phase micro-extraction gas chromatographic mass spectrometric (HS-SPME-GC-MS) analysis}

The extraction of the volatile compounds was performed by solid-phase micro-extraction (SPME) using polydimethylsiloxane 100- $\mu \mathrm{m}$ coated fiber (red fiber) purchased from Supelco (Bellefonte, PA, USA). For each sample under investigation, $3 \mathrm{~g}$ of finely ground material were transferred into a $15 \mathrm{~mL}$ screw cap vial (Supelco, Bellefonte, PA, USA) keeping the mixture under magnetic stirring (500 rpm). The sample was equilibrated for $20 \mathrm{~min}$ and then extracted, by exposing the fiber to the vapor phase for $20 \mathrm{~min}$. Equilibration and extraction temperature was $70{ }^{\circ} \mathrm{C}$. The fiber was conditioned in the gas-chromatograph (GC) injector at $250{ }^{\circ} \mathrm{C}$ for $15 \mathrm{~min}$ before each analysis. The GC analyses were accomplished by using a GC 6850 equipped with a split/ splitless injector and with a single-quadrupole mass spectrometric detector 5973 (both from Agilent Technologies, Santa Clara, CA, USA). The capillary chromatographic column was an Agilent Technologies HP-5-MS (30-m, 0.25-mm i.d., 0.25 - $\mu \mathrm{m}$ film thickness). The GC analysis was performed by thermally desorbing the fibers inside the GC injector, maintained at $250{ }^{\circ} \mathrm{C}$. The injection was performed in splitless mode (splitless time $4 \mathrm{~min}$ ), the insert used was a $0.75-\mathrm{mm}$ i.d. liner for SPME (Supelco, Bellefonte, PA, USA). The oven temperature was initially set at $50{ }^{\circ} \mathrm{C}$ for $5 \mathrm{~min}$, programmed at $10{ }^{\circ} \mathrm{C} \mathrm{min}{ }^{-1}$ to $300{ }^{\circ} \mathrm{C}$, and kept at $300{ }^{\circ} \mathrm{C}$ for $5 \mathrm{~min}$, resulting in a total run time of $35 \mathrm{~min}$. The carrier gas

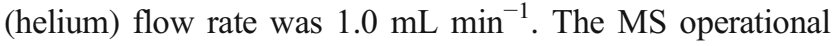
conditions were electron ionization (EI) $70 \mathrm{eV}$, transfer line and ion source temperature $250{ }^{\circ} \mathrm{C}$, quadrupole temperature $150{ }^{\circ} \mathrm{C}$, mass range $\mathrm{m} / \mathrm{z} 29-800$. The identity of compounds detected in the samples was confirmed by comparison of their mass spectra with reference spectra from the US National Institute of Standards and Technology.

\section{Elemental analysis}

The total mineralized elemental content was determined by ICP-MS after microwave-assisted acid digestion $\left(\mathrm{HNO}_{3}: \mathrm{H}_{2} \mathrm{O}_{2} 2: 1\right.$, conditions reported in Supplementary Material S1). This procedure did not allow a complete digestion of rubbers, probably because of quite large grain size (2$5 \mathrm{~mm}$ of diameter) and of the presence of crustal material as filler. We preferred not to add hydrofluoric or hydrochloric acid to avoid analytical interferences and higher blank values. The obtained results are reported in Table 1.

For the leaching tests, $0.5 \mathrm{~g}$ of rubber were treated with $25 \mathrm{~mL}$ of acetic acid 0.5 M. The extracting solution ( $\mathrm{pH} 3$ ) was chosen in order to overestimate the extraction efficiency occurring in the field. The leaching tests of SBR was performed in three ways: (i) mechanical agitation for $24 \mathrm{~h}$ by a rotary shaker (SB2, Cheimika, SA, Italy) at ambient temperature; (ii) ultrasonic-assisted extraction (USE; 50/60 Hz, $180 \mathrm{~W}$; Ultrasonic bath UTA 15, Falc Istruments S.r.1., Lurano, BG, Italy) of SBR for variable times (15-250 min), using a tailor-made rotating device to ensure the homogeneity of ultrasound irradiation; (iii) MAE using a two-step temperature-time program. In the first step, the temperature was linearly increased to $70^{\circ} \mathrm{C}$ in $5 \mathrm{~min}$ with a maximum power of $1000 \mathrm{~W}$; in the second step, the temperature was kept at $70^{\circ} \mathrm{C}$ for $45 \mathrm{~min}$.

The leaching tests of the other materials were performed only by MAE.

The extracted solutions were filtered with $0.45 \mu \mathrm{m}$ Millipore nitrate cellulose (NC) filters and mixed with $1 \%$ of nitric acid (Suprapur Merck). Ba, Ca, Cu, Fe, K, Mg, Mn, P, $\mathrm{Si}$, and $\mathrm{Zn}$ were analyzed by ICP-OES. After a 1:10 dilution with ultra-pure water, $\mathrm{As}, \mathrm{Be}, \mathrm{Cd}, \mathrm{Co}, \mathrm{Cr}, \mathrm{Li}, \mathrm{Ni}, \mathrm{Pb}, \mathrm{Sb}, \mathrm{Se}$, $\mathrm{Sn}, \mathrm{Sr}, \mathrm{Ti}, \mathrm{Tl}$, and V were analyzed by ICP-MS. The instrumental operating parameters were as previously described (Canepari et al. 2006, 2013). Standard solutions for six-point calibration were matrix-matched.

\section{SEM-EDS}

The analytical and morphological investigation was carried out by scanning electron microscopy LEO 1450VP coupled with a microanalysis system INCA 300 (SEM-EDS). The apparatus operates under variable pressure conditions, allowing the study also of non-conductive samples.

For the analysis of the samples, $100 \mu \mathrm{L}$ of the extracted solution (before filtration) was settled on graphite frames for SEM; the solution was then evaporated at room temperature in an appropriate room to avoid dust sedimentation.

\section{Results and discussion}

SEM-EDS analyses of the crumb rubber materials were performed in order to obtain a qualitative description of their morphology and elemental composition. As shown in Fig. 1, the various rubber grains present very different morphologies. The NR grains have a very porous surface and the presence of materials used as filler can be noticed; the TPE granulates have a smooth surface; the SBR granulates present very small splits but the surface appears generally compact. In all the 
Table 1 Total mineralized elemental concentrations ( $\mathrm{mg} / \mathrm{kg}$, dry weight) in rubbers (mean values and standard deviation, six replicates)

\begin{tabular}{|c|c|c|c|c|c|}
\hline Elements & SBR & TPE & NR 1 & NR2 & NR3 \\
\hline As & $1.2 \pm 0.1$ & $0.17 \pm 0.01$ & $0.43 \pm 0.02$ & $0.77 \pm 0.01$ & $0.65 \pm 0.03$ \\
\hline $\mathrm{Ba}$ & $10 \pm 5$ & $1.4 \pm 0.6$ & $3.7 \pm 0.5$ & $4.00 \pm 2$ & $6.1 \pm 0.5$ \\
\hline $\mathrm{Be}$ & $0.022 \pm 0.002$ & $0.024 \pm 0.001$ & $0.012 \pm 0.001$ & $0.010 \pm 0.001$ & $0.017 \pm 0.001$ \\
\hline $\mathrm{Ca}$ & $3646 \pm 307$ & $249,987 \pm 33,319$ & $316,818 \pm 18,853$ & $301,249 \pm 15,688$ & $284,787 \pm 11,009$ \\
\hline $\mathrm{Cd}$ & $3.2 \pm 0.1$ & $0.053 \pm 0.003$ & $0.086 \pm 0.006$ & $0.092 \pm 0.001$ & $0.080 \pm 0.002$ \\
\hline Co & $408 \pm 18$ & $0.58 \pm 0.03$ & $0.8 \pm 0.02$ & $0.86 \pm 0.06$ & $0.83 \pm 0.01$ \\
\hline $\mathrm{Cr}$ & $6.63 \pm 0.02$ & $1.8 \pm 02$ & $8.3 \pm 2.3$ & $5.2 \pm 0.2$ & $9 \pm 2$ \\
\hline $\mathrm{Cu}$ & $284 \pm 0.1$ & $73 \pm 6$ & $61 \pm 6$ & $97 \pm 8$ & $64 \pm 7$ \\
\hline $\mathrm{Fe}$ & $6279 \pm 261$ & $1623 \pm 1808$ & $8961 \pm 245$ & $13,905 \pm 101$ & $10,660 \pm 296$ \\
\hline K & $577 \pm 24$ & $57 \pm 3$ & $85 \pm 13$ & $73 \pm 8$ & $186 \pm 9$ \\
\hline $\mathrm{Li}$ & $2.6 \pm 0.4$ & $14.4 \pm 0.5$ & $4 \pm 2$ & $15 \pm 2$ & $24 \pm 8$ \\
\hline $\mathrm{Mg}$ & $497 \pm 35$ & $1697 \pm 81$ & $6554 \pm 804$ & $8878 \pm 1680$ & $8439 \pm 1644$ \\
\hline $\mathrm{Mn}$ & $45 \pm 3$ & $6,2 \pm 0,3$ & $20 \pm 6$ & $13 \pm 1$ & $20 \pm 5$ \\
\hline $\mathrm{Ni}$ & $5.45 \pm 0.03$ & $7.6 \pm 0.6$ & $6.7 \pm 1.1$ & $5.4 \pm 0.4$ & $6.3 \pm 0.9$ \\
\hline $\mathrm{P}$ & $257 \pm 8$ & $79 \pm 9$ & $66 \pm 7$ & $88 \pm 16$ & $83 \pm 15$ \\
\hline $\mathrm{Pb}$ & $35 \pm 7$ & $0.1 \pm 0.04$ & $2 \pm 00.6$ & $1.2 \pm 0.1$ & $1.5 \pm 0.5$ \\
\hline $\mathrm{Sb}$ & $1.3 \pm 0.9$ & $0.038 \pm 0.004$ & $0,07 \pm 0.01$ & $0,06 \pm 0.01$ & $0.08 \pm 0.01$ \\
\hline $\mathrm{Se}$ & $0.5 \pm 0.04$ & $0.05 \pm 0.01$ & $0.18 \pm 0.06$ & $0.27 \pm 0.01$ & $0.22 \pm 0.06$ \\
\hline $\mathrm{Si}$ & $574 \pm 16$ & $459 \pm 30$ & $362 \pm 79$ & $281 \pm 43$ & $561 \pm 58$ \\
\hline $\mathrm{Sn}$ & $2.1 \pm 0.1$ & $0.048 \pm 0.003$ & $0.21 \pm 0.02$ & $0.21 \pm 0.02$ & $0.34 \pm 0.01$ \\
\hline $\mathrm{Sr}$ & $8 \pm 2$ & $51 \pm 3$ & $111 \pm 23$ & $83 \pm 5$ & $166 \pm 20$ \\
\hline $\mathrm{Ti}$ & $27 \pm 1$ & $46 \pm 2$ & $22 \pm 5$ & $18 \pm 3$ & $36 \pm 3$ \\
\hline $\mathrm{Tl}$ & $0.28 \pm 0.05$ & $0.064 \pm 0.004$ & $0.38 \pm 0.03$ & $0.46 \pm 0.02$ & $0.52 \pm 0.01$ \\
\hline V & $2.1 \pm 0.2$ & $0.72 \pm 0.01$ & $1.1 \pm 0.3$ & $0.71 \pm 0.03$ & $1.9 \pm 0.3$ \\
\hline $\mathrm{Zn}$ & $26,984 \pm 912$ & $5 \pm 0.1$ & $4 \pm 1$ & $12 \pm 1$ & $14 \pm 1$ \\
\hline
\end{tabular}

three types of granulates, we could notice the presence of inorganic species (lighter points), whose nature changes with the kind of material. Table 2 reports the mean elemental composition of each material obtained by EDS analyses (spectra are reported in Supplementary Material S2). Although these data only refers to the grain surface and may have been influenced by the strong $\mathrm{C}$ signal due to the graphite substrate, elemental composition seemed to be fairly stable, with relative standard deviation of the order of $10-20 \%$. The different materials presented some common elements, such as $\mathrm{C}$ and $\mathrm{Si}$ (silicates), used in rubbers as filler systems to increase abrasion resistance and in tires to increase rolling resistance and wet skid properties, and also $\mathrm{Ca}$ (limestone or calcium carbonate), $\mathrm{Mg}$ (talc or magnesium silicate), and $\mathrm{Al}$ (kaolin clay or hydrous aluminum silicate and mica or potassium aluminum silicate), used as additional filler systems (Rodgers and Waddell 2013; Pavilonis et al. 2014). In the TPE and SBR granulates, the percentage of $\mathrm{S}$, used as vulcanization agent, is of 0.1 and $1,3 \%$, respectively; in the SBR granulates, about $1 \%$ of $\mathrm{Zn}$ is present as vulcanization activator (Verschoor 2007; Wik and Dave 2009; Krüger et al. 2012, 2013; Schilirò et al. 2013).

\section{Thermogravimetric analysis}

The thermogravimetric profiles of the different materials are reported in Fig. 2. Thermoanalytical techniques, in particular thermogravimetry, are very useful tools in material characterization because they do not require any sample pretreatment. This fact allows the analysis of each sample providing the most complete outcoming information, without any sample loss or modification of the original sample composition (Perrino et al. 2012).

The heating program was settled to reproduce the hardest stress condition of the material in real outdoor conditions. Each sample was heated up to $70{ }^{\circ} \mathrm{C}$ and left in isothermal mode to simulate the worst conditions during summer. Finally, the temperature was raised to $150{ }^{\circ} \mathrm{C}$.

The TGA profiles of SBR show a weight loss of less than $1 \%$ at $70^{\circ} \mathrm{C}$, followed by another small weight loss at $150^{\circ} \mathrm{C}$. NR weight loss was much more consistent and reached about $3 \%$ at $70^{\circ} \mathrm{C}$, whereas in the case of TPE, the weight loss was not significant. The observed loss at $70{ }^{\circ} \mathrm{C}$ are probably mainly due to water, but the possible desorption of volatile organic species deserves further investigations. 

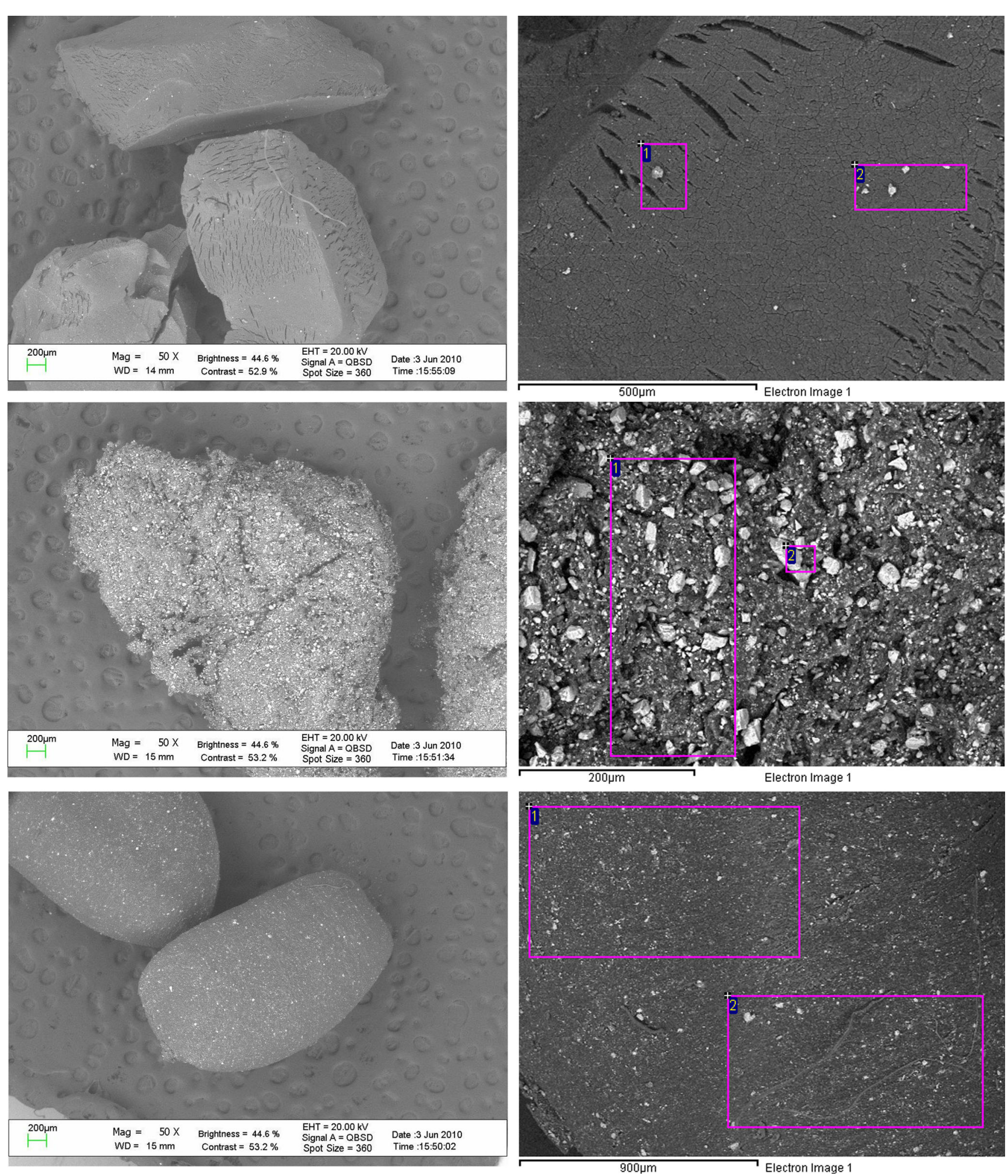

Fig. 1 SEM micrographs (left panel) and field chosen for EDS microanalysis (right panel) of the recycled scrap tires (upper panel),

natural rubber (middle panel), and thermoplastic elastomer crumb (lower panel)

\section{Solid-phase micro-extraction}

The headspace solid-phase micro-extraction followed by gas chromatography coupled to mass spectrometry was carried

out to obtain a qualitative picture of the volatile compounds released by each of the investigated materials. As can be seen in Fig. 3, where individual and overlaid chromatograms are reported, the typical hump given by mineral oils was found 
Table 2 Relative concentration (\%) of major elements measured by EDS in the fields of Fig. 1

\begin{tabular}{lllllllllll}
\hline & Spectrum & $\mathrm{C}$ & $\mathrm{O}$ & $\mathrm{Mg}$ & $\mathrm{Al}$ & $\mathrm{Si}$ & $\mathrm{S}$ & $\mathrm{Ca}$ & $\mathrm{Fe}$ & $\mathrm{Zn}$ \\
\hline SBR & 1 & 75.2 & 20.1 & 0.1 & 0.5 & 1.3 & 1.2 & 0.2 & 0.4 & 1.0 \\
& 2 & 78.3 & 17.3 & 0.1 & 0.3 & 0.8 & 1.3 & 0.6 & 0.2 & 1.1 \\
NR & 3 & 57.4 & 20.6 & 0.1 & 0.2 & $<0.1$ & $<0.1$ & 21.0 & 0.8 & $<0.1$ \\
& 4 & 49.9 & 20.2 & $<0.1$ & 0.6 & $<0.1$ & $<0.1$ & 28.5 & 0.7 & $<0.1$ \\
TPE & 5 & 75.3 & 18.7 & $<0.1$ & 0.1 & 2.0 & 0.1 & 3.8 & $<0.1$ & $<0.1$ \\
& 6 & 72.4 & 19.5 & $<01$ & 0.2 & 2.2 & 0.1 & 5.6 & $<0.1$ & $<0.1$ \\
& & & & & & & & & & \\
\hline
\end{tabular}

(Neukom et al. 2002; Fiorini et al. 2008, 2010) with both even and odd number linear alkanes laying on the hump, confirming the mineral oil origin of the alkanes mixture.

The SBR sample released low relative amount of mineral alkanes, while both the NR and the TPE samples released a major quantity of mineral oils, probably used as additive in their production. The profile and range of alkanes detected were identical in the two samples, including isomers from $\mathrm{C} 14$ to $\mathrm{C} 25$, with the largest amount being composed by alkanes around C17-C22. This means a low-viscosity mineral oil, known to present higher toxicological problems than highviscosity mineral oil (JECFA 1995; EFSA 2012). However, it
Fig. 2 Thermal ramp (upper panel) and TG curve for the thermal degradation of TPE, SBR, and NR (lower panel)
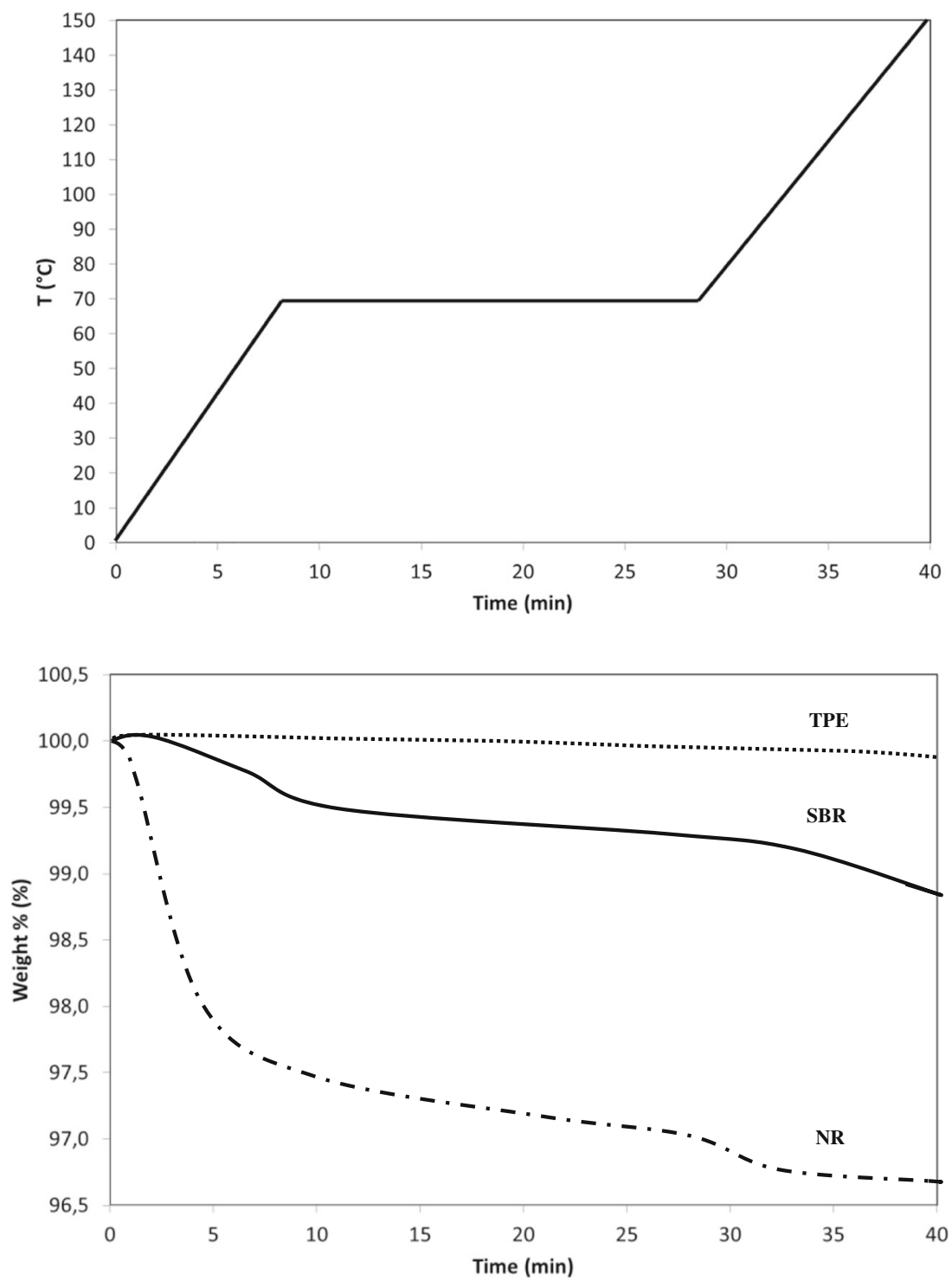
Fig. 3 Chromatograms obtained from the HS-SPME-GC-MS analysis of the samples SBR (a), NR (b), and TPE (c) a SBR

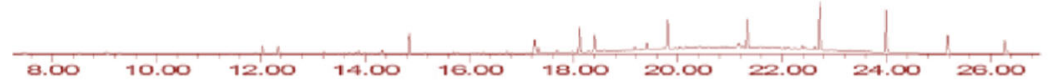

b NR

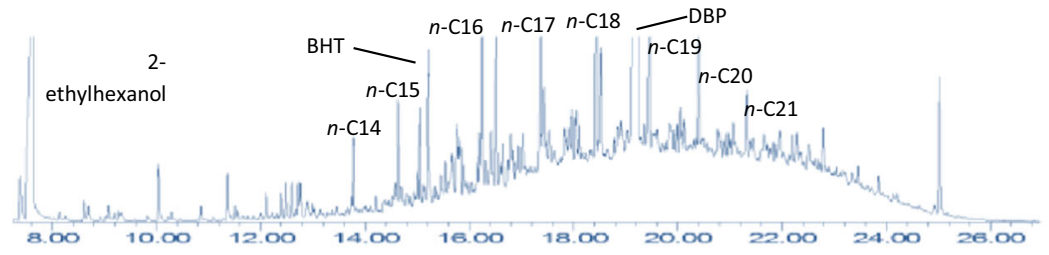

c TPE

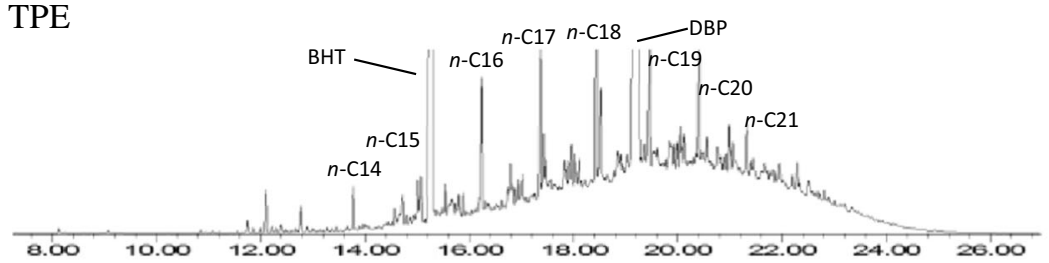

d Overlaid chromatograms

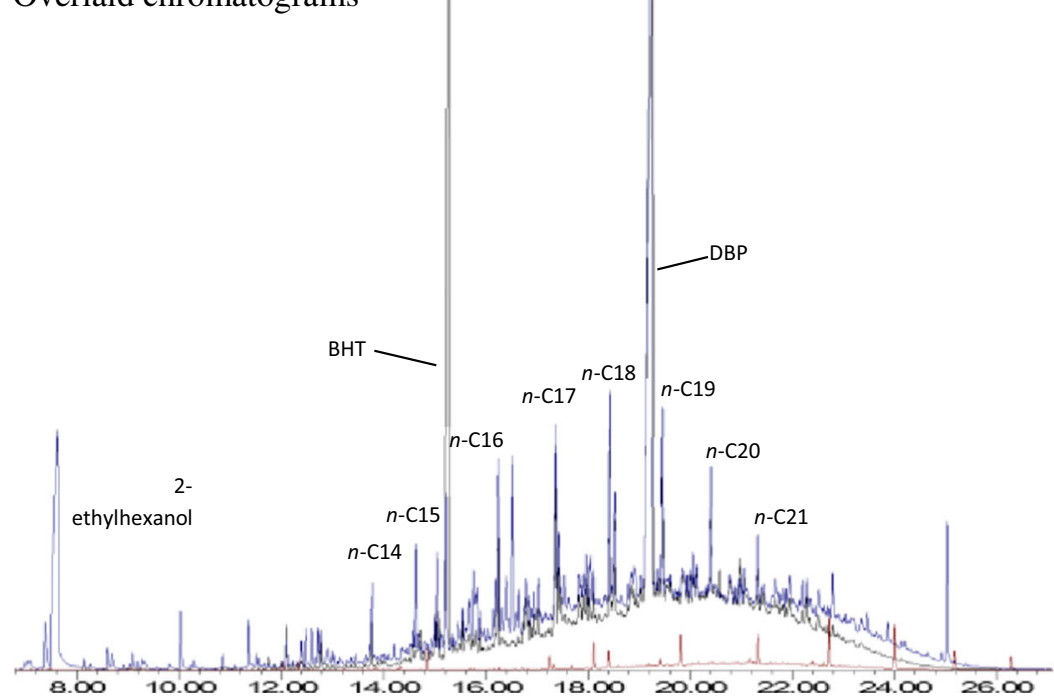

is worth noting that the presence of higher molecular weight alkanes cannot be excluded, as the fiber efficiently extracts only volatile compounds.

The presence of diisobutyl phthalate (DBP) was clearly detected in both TPE and NR, in similar amounts. Furthermore, NR released 2-ethylhexanol, a compound used as feedstock in the preparation of plasticizers or as solvent (e.g., in petroleum derivatives), while TPE released butylated hydroxytoluene (BHT), a typical synthetic antioxidant.

\section{Elemental analysis}

Some preliminary tests were addressed to the choice of the leaching conditions that allow an acceptable repeatability of the measurements. In these tests, we evaluated the performances of USE and MAE, which had been considered interesting alternatives to the conventional mechanical agitation for the leaching tests (Canepari et al. 2005). It is worth noting that during the USE or MAE, the materials are submitted to mechanical stress (USE) or to the action of temperature and pressure (MAE); these processes exert conditions that accelerate the aging of the material and extract substances that could potentially be released from the turf. The application of these extractive techniques may then provide some additional and interesting information regarding the behavior of rubber under physical stress.

Figure 4 shows the elemental concentrations measured in the extracting solution after exposing SBR materials to ultrasounds (US) for $45 \mathrm{~min}$ and $180 \mathrm{~min}$. It can be noticed that the extracted amounts increased with time. It is well known that 

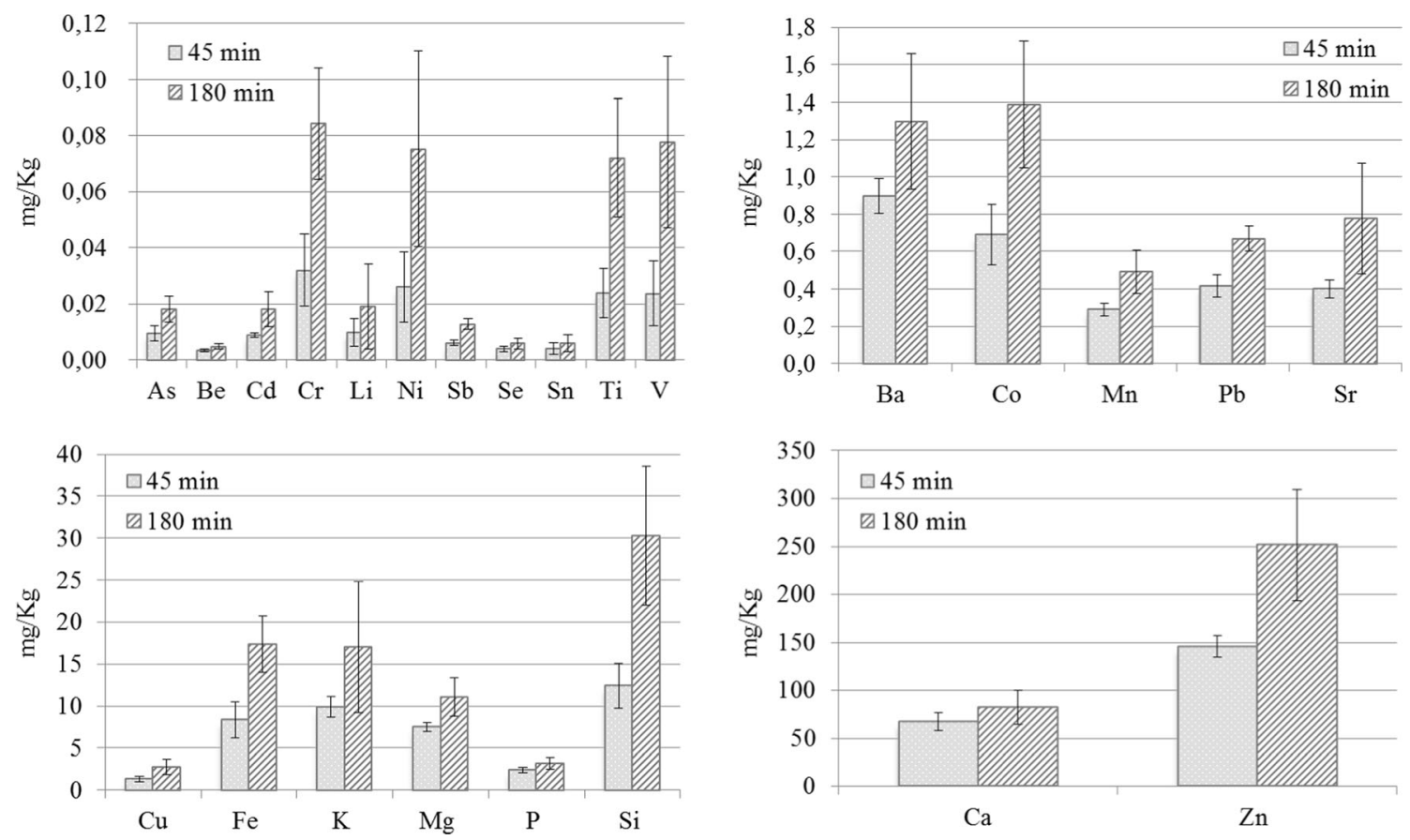

Fig. 4 Elemental concentration (mg/kg) obtained after 45 and $180 \mathrm{~min}$ of US irradiation. Error bars represent the standard deviation from eight replicates

the exposure of solids to ultrasound leads to structural changes in their surface morphology (Suslick and Doktycz 1989; Canepari et al. 2005); the impact of the ultrasound jet and its associated shock wave erode the solid, leading to localized fragmentation of particles (Benjamin and Ellis 1966; Preece and Hansson 1981; Lauterborn and Hentschel 1985; De Souza-Barboza et al. 1988). The obtained results seem then to reveal a progressive fragmentation of grains during the ultrasound irradiation, with a consequent increase of the contact surfaces and the availability of metals. Results shown in Fig. 4 also evidenced that the repeatability markedly decreased with the increase of US exposure time, probably because the fragmentation process of grains could not be efficiently controlled. It is worth noting that, as already remarked, the grains are quite large and contain high concentrations of substances, mainly inorganic and potentially soluble, embedded in the grain. Differently from soils, sediments and other environmental matrices subject to leaching tests granulates, because of their elastic properties, cannot be subjected to pulverization and size selection before extraction, so that the extraction of embedded substances cannot be completed nor repeatable.

The action of US on the morphology of grains was confirmed by SEM-EDS. Figure 5 shows the images of the SBR and NR after $45 \mathrm{~min}$ of US application. It can be noticed how ultrasound succeeds in crumbling parts of the material, spreading solid particles of small sizes (down to less than $10 \mu \mathrm{m}$ ).

The EDS analysis (Table 3; spectra reported in Supplementary Material S3a and S3b) showed that the formed particles were in part constituted by filler materials (Al, Ca, $\mathrm{K}, \mathrm{Mg}, \mathrm{Si}$; Rodgers and Waddell 2013) and in part constituted by small rubber grains. For comparison, Fig. 5 also shows the SEM images of used natural rubber grains (NR), crushed and mixed in a mortar with a pestle, to simulate the foot traffic on the fields. It can be noticed how the arranged particles are very similar to those obtained as a consequence of USE, in size and composition. It is worth noting that NR seems to show a certain fragility, mainly as a consequence of the rubber hardening due to the exposition to the environmental conditions; the possibility of a release of inhalable particles as a consequence of mechanical stress needs then to be considered. TPE showed a higher mechanical resistance and did not form small particle after US exposition or mechanical crushing.

In case of MAE, preliminary tests showed that, as expected, the extractable amounts tend to increase with temperature and irradiation time. At $70{ }^{\circ} \mathrm{C}$, the extracted amounts reached constant values only after about 45 min of treatment, a very long time if compared with the usual MAE extraction times; this confirms a slow extractive kinetic, probably related, also in this case, to the grain size. After MAE, grains released small particles in solution, which maintained the elemental composition typical of the original material. The effect of microwaves was probably related to a combination of the action of temperature, responsible for a partial loss of rubbers thermoplastic properties, and of mechanisms of dipoles rotation and ionic conduction inside the treated matrix (Camel 2001). In any case, these results confirmed, once more, the fragility of grains. 

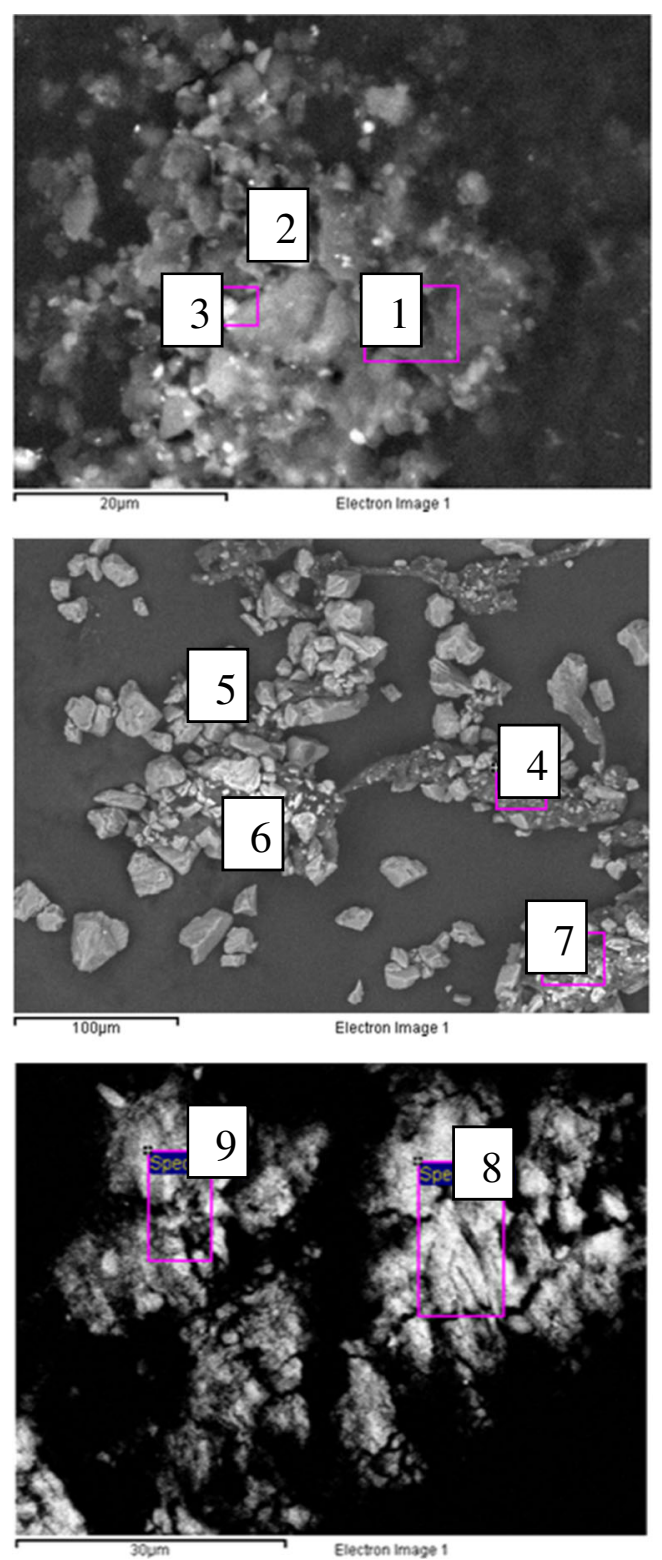

Fig. 5 Field chosen for EDS micro-analysis of the recycled scrap tires (upper panel) and natural rubber (middle panel) after USE. The lower panel is related to NR crushed and mixed in a mortar
Table 4 Comparison of leachable elemental concentrations $(\mathrm{mg} / \mathrm{kg}$, dry weight) in SBR obtained by mechanical agitation, USE, and MAE

\begin{tabular}{|c|c|c|c|c|}
\hline Elements & $\mathrm{LOQ}^{\mathrm{a}}$ & $\begin{array}{l}\text { Mechanical } \\
\text { agitation }^{\text {b }}\end{array}$ & $\mathrm{USE}^{\mathrm{c}}$ & MAE $^{d}$ \\
\hline As & 0.010 & $0.026 \pm 0.002$ & $0.018 \pm 0.005$ & $<\mathrm{LOQ}$ \\
\hline $\mathrm{Ba}$ & 0.05 & $1.14 \pm 0.02$ & $1.3 \pm 0.4$ & $0.90 \pm 0.03$ \\
\hline $\mathrm{Be}$ & 0.002 & $0.004 \pm 0.001$ & $0.005 \pm 0.001$ & $0.005 \pm 0.001$ \\
\hline $\mathrm{Ca}$ & 6 & $112 \pm 16$ & $82 \pm 18$ & $99 \pm 13$ \\
\hline $\mathrm{Cd}$ & 0.002 & $0.017 \pm 0.001$ & $0.018 \pm 0.006$ & $0.0197 \pm 0.0004$ \\
\hline Co & 0.003 & $1.6 \pm 0.4$ & $1.4 \pm 0.3$ & $2.0 \pm 0.5$ \\
\hline $\mathrm{Cr}$ & 0.02 & $0.05 \pm 0.01$ & $0.08 \pm 0.02$ & $0.05 \pm 0.02$ \\
\hline $\mathrm{Cu}$ & 0.04 & $3.5 \pm 0.2$ & $2.7 \pm 0.9$ & $2.4 \pm 0.5$ \\
\hline $\mathrm{Fe}$ & 1 & $18 \pm 1$ & $17 \pm 3$ & $15 \pm 1$ \\
\hline K & 3 & $24 \pm 8$ & $17 \pm 8$ & $12 \pm 1$ \\
\hline $\mathrm{Li}$ & 0.002 & $0.013 \pm 0.003$ & $0.019 \pm 0.015$ & $0.009 \pm 0.001$ \\
\hline $\mathrm{Mg}$ & 2 & $11 \pm 1$ & $11 \pm 2$ & $12 \pm 2$ \\
\hline $\mathrm{Mn}$ & 0.1 & $0.49 \pm 0.01$ & $0.49 \pm 0.09$ & $0.47 \pm 0.01$ \\
\hline $\mathrm{Ni}$ & 0.01 & $0.04 \pm 0.01$ & $0.08 \pm 0.03$ & $0.05 \pm 0.01$ \\
\hline $\mathrm{P}$ & 1 & $4 \pm 1$ & $3.2 \pm 0.7$ & $3.7 \pm 0.1$ \\
\hline $\mathrm{Pb}$ & 0.01 & $0.72 \pm 0.03$ & $0.67 \pm 0.07$ & $0.66 \pm 0.01$ \\
\hline $\mathrm{Sb}$ & 0.03 & $<$ LOQ & $<\mathrm{LOQ}$ & $<\mathrm{LOQ}$ \\
\hline $\mathrm{Se}$ & 0.02 & $<$ LOQ & $<$ LOQ & $<$ LOQ \\
\hline $\mathrm{Si}$ & 1 & $10 \pm 2$ & $30 \pm 8$ & $10.6 \pm 0.1$ \\
\hline $\mathrm{Sn}$ & 0.01 & $<$ LOQ & $<$ LOQ & $<$ LOQ \\
\hline $\mathrm{Sr}$ & 0.02 & $0.53 \pm 0.02$ & $0.8 \pm 0.3$ & $0.46 \pm 0.02$ \\
\hline $\mathrm{Ti}$ & 0.01 & $0.03 \pm 0.02$ & $0.07 \pm 0.02$ & $0.018 \pm 0.006$ \\
\hline $\mathrm{Tl}$ & 0.002 & $<$ LOQ & $<\mathrm{LOQ}$ & $<$ LOQ \\
\hline $\mathrm{V}$ & 0.02 & $0.02 \pm 0.01$ & $0.08 \pm 0.03$ & $0.03 \pm 0.01$ \\
\hline $\mathrm{Zn}$ & 0.2 & $246 \pm 2$ & $251 \pm 58$ & $250 \pm 1$ \\
\hline
\end{tabular}

${ }^{\mathrm{a}} \mathrm{LOQ}(\mathrm{mg} / \mathrm{Kg})$ were calculated as LOQ $=\mathrm{s}_{\mathrm{b}}+10 \sigma_{\mathrm{b}}(\mathrm{IUPAC}, 1978)$

b $24 \mathrm{~h}$

${ }^{\mathrm{c}} 180 \mathrm{~min}$

${ }^{\mathrm{d}} 45 \min , 70^{\circ} \mathrm{C}$

In Table 4, the concentrations of elements extracted from the SBR material, which is the material with the highest concentration of toxic elements (see Table 1), by mechanical

Table 3 Relative concentration (weight \%) of major elements measured by EDS in the fields of Fig. 5

\begin{tabular}{|c|c|c|c|c|c|c|c|c|c|c|c|c|c|c|c|}
\hline & Spectrum & $\mathrm{C}$ & $\mathrm{O}$ & $\mathrm{Na}$ & $\mathrm{Mg}$ & $\mathrm{Al}$ & $\mathrm{Si}$ & $\mathrm{S}$ & $\mathrm{Cl}$ & K & $\mathrm{Ca}$ & $\mathrm{Ti}$ & $\mathrm{Fe}$ & $\mathrm{Cu}$ & $\mathrm{Zn}$ \\
\hline \multirow[t]{3}{*}{ SBR } & 1 & 69.1 & 24.0 & - & 0.4 & 0.7 & 1.8 & 1,0 & 0.2 & 0.2 & 0.8 & - & 0.6 & $<0.1$ & 1.2 \\
\hline & 2 & 35.0 & 45.1 & - & 0.4 & 0.7 & 17.6 & 0,2 & $<0.1$ & 0.2 & 0.2 & - & 0.2 & 0.1 & 0.3 \\
\hline & 3 & 57.0 & 31.6 & - & 1.0 & 1.3 & 1.8 & 0,9 & 0.1 & 0.1 & 0.7 & - & 4.3 & 0.2 & 1.0 \\
\hline \multirow{4}{*}{$\begin{array}{l}\text { NR after } \\
\text { ultrasonic treatment }\end{array}$} & 4 & 69.9 & 19.4 & - & 0.1 & - & - & - & - & - & 9.7 & 0,2 & 0.7 & - & - \\
\hline & 5 & 17.3 & 41.8 & - & 0.3 & - & - & - & - & - & 40.3 & $<0.1$ & 0.2 & - & - \\
\hline & 6 & 21.2 & 53.3 & - & 0.2 & - & - & - & - & - & 25.4 & $<0.1$ & $<0.1$ & - & - \\
\hline & 7 & 63.3 & 23.2 & - & 0.1 & - & - & - & - & - & 12.5 & 0.2 & 0.7 & - & - \\
\hline \multirow[t]{2}{*}{ NR crushed } & 8 & 43.0 & 32.4 & 5.2 & 0.4 & 2.0 & 8.6 & - & 6.3 & 0.7 & 1.0 & - & 0.4 & - & - \\
\hline & 9 & 40.7 & 40.9 & 0.5 & 0.6 & 2.6 & 12.0 & - & 0.2 & 0.9 & 1.2 & - & 0.4 & - & - \\
\hline
\end{tabular}


Table 5 Leachable elemental concentrations (mg/kg, dry weight) in TPE, NR1, NR2, and NR3 obtained by MAE

\begin{tabular}{|c|c|c|c|c|}
\hline Elements & TPE & NR1 & NR2 & NR3 \\
\hline As & $<\mathrm{LOQ}^{*}$ & $0.015 \pm 0.005$ & $0.027 \pm 0.003$ & $0.020 \pm 0.001$ \\
\hline $\mathrm{Ba}$ & $<\mathrm{LOQ}^{*}$ & $0.077 \pm 0.009$ & $0.119 \pm 0.009$ & $0.224 \pm 0.027$ \\
\hline $\mathrm{Be}$ & $<\mathrm{LOQ}^{*}$ & $<\mathrm{LOQ}^{*}$ & $<\mathrm{LOQ}^{*}$ & $<\mathrm{LOQ}^{*}$ \\
\hline $\mathrm{Ca}$ & $265 \pm 4$ & $4407 \pm 106$ & $6905 \pm 62$ & $6668 \pm 181$ \\
\hline $\mathrm{Cd}$ & $<\mathrm{LOQ}^{*}$ & $0.0062 \pm 0.0004$ & $0.0100 \pm 0.0005$ & $0.0084 \pm 0.0004$ \\
\hline $\mathrm{Co}$ & $<\mathrm{LOQ}^{*}$ & $0.006 \pm 0.001$ & $0.011 \pm 0.001$ & $0.012 \pm 0.001$ \\
\hline $\mathrm{Cr}$ & $0.0046 \pm 0.0005$ & $<\mathrm{LOQ}^{*}$ & $<\mathrm{LOQ}^{*}$ & $<\mathrm{LOQ}^{*}$ \\
\hline $\mathrm{Cu}$ & $<\mathrm{LOQ}^{*}$ & $<\mathrm{LOQ}^{*}$ & $<\mathrm{LOQ}^{*}$ & $<\mathrm{LOQ}^{*}$ \\
\hline $\mathrm{Fe}$ & $<\mathrm{LOQ}^{*}$ & $<\mathrm{LOQ}^{*}$ & $<\mathrm{LOQ}^{*}$ & $<\mathrm{LOQ}^{*}$ \\
\hline $\mathrm{K}$ & $<\mathrm{LOQ}^{*}$ & $<\mathrm{LOQ}^{*}$ & $<\mathrm{LOQ}^{*}$ & $<\mathrm{LOQ}^{*}$ \\
\hline $\mathrm{Li}$ & $0.019 \pm 0.001$ & $0.037 \pm 0.005$ & $0.44 \pm 0.02$ & $0.53 \pm 0.03$ \\
\hline $\mathrm{Mg}$ & $2.1 \pm 0.1$ & $65 \pm 8$ & $82 \pm 2$ & $91 \pm 2$ \\
\hline Mn & $<\mathrm{LOQ}^{*}$ & $0.28 \pm 0.03$ & $0.34 \pm 0.01$ & $0.57 \pm 0.06$ \\
\hline $\mathrm{Ni}$ & $<\mathrm{LOQ}^{*}$ & $0.02 \pm 0.01$ & $0.016 \pm 0.001$ & $0.023 \pm 0.002$ \\
\hline $\mathrm{P}$ & $<\mathrm{LOQ}^{*}$ & $<\mathrm{LOQ}^{*}$ & $<\mathrm{LOQ}^{*}$ & $<\mathrm{LOQ}^{*}$ \\
\hline $\mathrm{Pb}$ & $0.010 \pm 0.002$ & $0.036 \pm 0.002$ & $0.049 \pm 0.005$ & $0.041 \pm 0.004$ \\
\hline $\mathrm{Sb}$ & $0.03 \pm 0.01$ & $0.050 \pm 0.004$ & $0.036 \pm 0.006$ & $0.048 \pm 0.006$ \\
\hline $\mathrm{Se}$ & $0.029 \pm 0.001$ & $0.107 \pm 0.003$ & $0.108 \pm 0.004$ & $0.12 \pm 0.01$ \\
\hline $\mathrm{Si}$ & $<\mathrm{LOQ}^{*}$ & $<\mathrm{LOQ}^{*}$ & $<\mathrm{LOQ}^{*}$ & $<\mathrm{LOQ}^{*}$ \\
\hline Sn & $0.010 \pm 0.001$ & $0.024 \pm 0.006$ & $0.032 \pm 0.011$ & $0.048 \pm 0.008$ \\
\hline $\mathrm{Sr}$ & $0.10 \pm 0.01$ & $3.4 \pm 0.4$ & $4.01 \pm 0.01$ & $7.6 \pm 0.3$ \\
\hline $\mathrm{Ti}$ & $<\mathrm{LOQ}^{*}$ & $0.010 \pm 0.001$ & $0.011 \pm 0.001$ & $0.013 \pm 0.001$ \\
\hline $\mathrm{Tl}$ & $0.054 \pm 0.004$ & $0.28 \pm 0.04$ & $0.38 \pm 0.04$ & $0.419 \pm 0.007$ \\
\hline $\mathrm{V}$ & $<\mathrm{LOQ} *$ & $<\mathrm{LOQ}^{*}$ & $<\mathrm{LOQ} *$ & $<\mathrm{LOQ}^{*}$ \\
\hline $\mathrm{Zn}$ & $<\mathrm{LOQ}^{*}$ & $0.23 \pm 0.04$ & $1.1 \pm 0.2$ & $1.6 \pm 0.2$ \\
\hline
\end{tabular}

${ }^{*} \mathrm{LOQ}(\mathrm{mg} / \mathrm{Kg})$ reported in Table 4

extraction, USE and MAE, are compared. It can be noticed that the mean values of extracted concentrations were in general comparable in the case of mechanical agitation and MAE, while they tended to increase after USE, at least for some elements (Ba, Cr, Li, Ni, Si, Sr, Ti, and V). The best analytical repeatability was obtained with the use of MAE, confirming the good performances of this extraction method, which allows a good control of the operative conditions (Camel 2001). MAE was then chosen for the evaluation of leachable concentration of elements from the other rubbers.

In Table 5, the elemental concentration extracted by MAE from TPE, NR1, NR2, and NR3 are compared. It can be noticed how natural rubber, which released concentrations markedly lower of $\mathrm{Ba}, \mathrm{Co}, \mathrm{Cu}, \mathrm{Fe}, \mathrm{Pb}$, and $\mathrm{Zn}$ with respect to $\mathrm{SBR}$ (Table 4), released significant concentrations of $\mathrm{Ca}, \mathrm{Mg}, \mathrm{Se}$, $\mathrm{Sr}$, and $\mathrm{Tl}$. With respect to the total mineralized elemental concentrations (Table 1), the leachable concentration is generally low (in most cases lower than 10\%), with the exception of $\mathrm{Sb}, \mathrm{Se}$, and $\mathrm{Tl}$, which are mainly in the form of soluble species (extraction percentage higher than $50 \%$ ). The data in Table 5 also show that most of the elements were released from TPE samples at low concentrations; relatively high concentrations were obtained only for $\mathrm{Mg}$ and $\mathrm{Ca}$.

The three NR samples gave very similar results and the elemental concentrations released from NR3 were compatible with a mixture of NR1 and NR2. Therefore, the aging does not seem to significantly modify the release of elements, at least in the considered conditions.

\section{Conclusions}

The chemical and morphological characterization of the considered crumb rubber materials put into evidence how potential risks for health and environment can arise from the exposition of rubbers to chemical and physical agents.

When exposed to a temperature of $70{ }^{\circ} \mathrm{C}$, which can be reached by the materials during the summer season, NR and TPE released gross amounts of organic species, much more consistent than SBR. In particular, the desorption of mineral oils from both materials, with a prevalence of toxicologically relevant low-viscosity alkanes in the range $\mathrm{C} 17-\mathrm{C} 22$ and 
plasticizers (diisobutyl phthalate), was clearly evidenced. Butylated hydroxytoluene was also identified between the compounds released from the new-generation TPE.

Concerning the release of elements, the leaching tests in slightly acidic conditions confirmed the presence of significant bio-accessible amounts of toxic metals (mainly $\mathrm{Zn}, \mathrm{Cu}$, and $\mathrm{Co}$ ) in SBR and evidenced quite high concentrations of leachable Se and $\mathrm{Tl}$ in NR; the elemental concentrations released by TPE were instead generally low.

NR resulted to be particularly sensitive to aging and crumbling phenomena, which lead to the formation of small particles, also in the inhalable fraction, made up of the inert materials used as fillers and of small rubber grain.

The use of natural rubber and of not-recycled thermoplastic materials, which are progressively replacing recycled tire scraps as synthetic turf fillers, does not seem to be adequately safe for human health, particularly when considering that children are the most exposed bracket of population. Exposure risks arising from the use of these materials deserve to be further deepened.

Acknowledgements This work was financed by the National Institute for Occupational Safety and Prevention, contract n. Prot. AOO-20/ 0001902/09. Dr. Angelo Marini is gratefully acknowledged for his valuable collaboration. Authors gratefully acknowledge Golden Plast S.p.A. (Potenza Picena, Italy) for providing the TPE new-generation material.

\section{References}

Benjamin TB, Ellis AT (1966) The collapse of cavitation bubbles and the pressures thereby produced against solid boundaries. Phil Trans R Soc Lond A 260:221-240

Birkholz DA, Belton KL, Guidotti TL (2003) Toxicological evaluation for the hazard assessment of tire crumb for use in public playgrounds. J Air Waste Manage Assoc 53:903-907

Bocca B, Forte G, Petrucci F, Costantini S, Izzo P (2009) Metals contained and leached from rubber granulates used in synthetic turf areas. Sci Total Environ 407:2183-2190

Camel V (2001) Recent extraction techniques for solid matrices - supercritical fluid extraction, pressurized fluid extraction and microwaveassisted extraction: their potential and pitfalls. Analyst 126:11821193

Canepari S, Astolfi ML, Moretti S, Curini R (2010) Comparison of extracting solutions for elemental fractionation in airborne particulate matter. Talanta 82:834-844

Canepari S, Cardarelli E, Ghighi S, Scimonelli L (2005) Ultrasound and microwave-assisted extraction of metals from sediment: a comparison with the BCR procedure. Talanta 66:1122-1130

Canepari S, Cardarelli E, Giuliano A, Pietrodangelo A (2006) Determination of metals, metalloids and non-volatile ions in airborne particulate matter by a new two-step sequential leaching procedure. Part A: Experimental design and optimization. Talanta 69: 581-587

Canepari S, Padella F, Astolfi ML, Marconi E, Perrino C (2013) Elemental concentration in atmospheric particulate matter: estimation of nanoparticle contribution. Aerosol Air Qual Res 13:1619 1629
Canepari S, Perrino C, Olivieri F, Astolfi ML (2008) Characterisation of the traffic sources of PM through size-segregated sampling, sequential leaching and ICP analysis. Atmos Environ 42:8161-8175

Cheng H, Hu Y, Reinhard M (2014) Environmental and health impacts of artificial turf: a review. Environ Sci Technol 48:2114-2129

Claudio L (2008) Synthetic turf: health debate takes root. Environ Health Perspect 116:A116-A122

De Souza-Barboza JC, Pétrier C, Luche JL (1988) Ultrasound in organic synthesis. Some fundamental aspects of the sonochemical Barbier reaction. J Org Chem 53:1212-1218

EFSA (European Food Safety Authority) (2012) Scientific opinion on mineral oil hydrocarbons in food. EFSA J 10(6):2704 1-185. http://www.efsa.europa.eu/en/efsajournal/pub/2704.htm

Environmental Protection Agency (EPA) US (2009) A scoping-level field monitoring study of synthetic turf fields and playgrounds. EPA/600/ R-09/135

Fiorini D, Fiselier K, Biedermann M, Ballini R, Coni E, Grob K (2008) Contamination of grape seed oils with mineral oil paraffins. J Agric Food Chem 56:11245-11250

Fiorini D, Paciaroni A, Gigli F, Ballini R (2010) A versatile splitless injection GC-FID method for the determination of mineral oil paraffins in vegetable oils and dried fruit. Food Control 21:1155-1160

Ginsberg G, Toal B, Simcox N, Bracker A, Golembiewski B, Kurland T, Hedman C (2011) Human health risk assessment of synthetic turf fields based upon investigation of five fields in Connecticut. J Toxicol Environ Health Part A 74:1150-1174

Gomes J, Mota H, Bordado J, Cadete M, Sarmento G, Ribeiro A, Baiao M, Fernandes J, Pampulim V, Custódio M, Veloso I (2010) Toxicological assessment of coated versus uncoated rubber granulates obtained from used tires for use in sport facilities. J Air Waste Manage Assoc 60:741-746

IUPAC, Analytical Chemistry Division (1978) Nomenclature, symbol, units and their usage in spectrochemical analysis. II. Data interpretation. Spectrochim Acta B 33(6):241-246

JECFA (Joint FAO/WHO Expert Committee on Food Additives) (1995) Summary of evaluations performed by the Joint FAO/WHO Expert Committee on Food Additives. http://www.inchem.org/documents/ jecfa/jeceval/jec_1655.htm

Kim S, Yang JY, Kim HH, Yeo IY, Shin DC, Lim YW (2012) Health risk assessment of lead ingestion exposure by particle sizes in crumb rubber on artificial turf considering bioavailability. Environ Health Toxicol 27:1-10

Kreider ML, Panko PJ, McAtee BL, Sweet LI, Finley BL (2010) Physical and chemical characterization of tire-related particles: comparison of particles generated using different methodologies. Sci Total Environ 408:652-659

Krüger O, Kalbe U, Berger W, Nordhau K, Christoph G, Walzel H-P (2012) Comparison of batch and column tests for the elution of artificial turf system components. Environ Sci Technol 46:1308513092

Krüger O, Kalbe U, Richter E, Egeler P, Römbke J, Berger W (2013) New approach to the ecotoxicological risk assessment of artificial outdoor sporting grounds. Environ Pollut 175:69-74

Kwon E, Castaldi MJ (2009) Fundamental understanding of the thermal degradation mechanisms of waste tires and their air pollutant generation in a $\mathrm{N}_{2}$. Atmos Environ Sci Technol 43:5996-6002

Lauterborn W, Hentschel W (1985) Cavitation bubble dynamics studied by high speed photography and holography: part one. Ultrasonics 23:260-268

Li X, Berger W, Musante C, Mattina MI (2010) Characterization of substances released from crumb rubber material used on artificial turf fields. Chemosphere 80:279-285

Llompart M, Sanchez-Prado L, Lamas JP, Garcia-Jares C, Roca E, Dagnac T (2013) Hazardous organic chemicals in rubber recycled tire playgrounds and pavers. Chemosphere 90:423-431 
Neukom HP, Grob K, Biedermann M, Noti A (2002) Food contamination by $\mathrm{C} 20-\mathrm{C} 50$ mineral paraffins from the atmosphere. Atmos Environ 36:4839-4847

Pavilonis BT, Weisel CP, Buckley B, Lioy PJ (2014) Bioaccessibility and risk exposure to metals and SVOCs in artificial turf field fill materials and fibers. Risk Anal 34(1):44-55

Perrino C, Marconi E, Tofful L, Farao C, Materazzi S, Canepari S (2012) Thermal stability of inorganic and organic compounds in atmospheric particulate matter. Atmos Environ 54:36-43

Preece CM, Hansson I (1981) A metallurgical approach to cavitation erosion. Adv Mech Phy Surf 1:199-253

Quek A, Balasubramanian R (2009) An algorithm for the kinetics of tire pyrolysis under different heating rates. J Hazard Mater 166: $126-132$

Rodgers B, Waddell W (2013) The science of rubber compounding. In: Mark JE, Herman B, Roland CM (eds) The science and technology of rubber, 4th edn. Elsevier, Amsterdam, pp 417-470

Ruffino B, Fiore S, Zanetti MC (2013) Environmental-sanitary risk analysis procedure applied to artificial turf sports fields. Environ Sci Pollut Res Int 20:4980-4992

Sadiktsis I, Bergvall C, Johansson C, Westerholm R (2012) Automobile tires - a potential source of highly carcinogenic dibenzopyrenes to the environment. Environ Sci Technol 46:3326-3334

Schilirò T, Traversi D, Degan R, Pignata C, Alessandria L, Scozia D, Bono R, Gilli G (2013) Artificial turf football fields: environmental and mutagenicity assessment. Arch Environ Contam Toxicol 64:1-11

Serensits TJ, McNitt AS, Petrunak DM (2011) Human health issues on synthetic turf in the USA. Proc IMechE J Sports Eng Technol Part P 225:1-8
Simcox NJ, Bracker A, Ginsberg G, Toal B, Golembiewski B, Kurland T, Hedman C (2011) Synthetic turf field investigation in Connecticut. J Toxicol Environ Health Part A 74:1133-1149

Simon R (2010) Review of the impacts of crumb rubber in artificial turf applications. Prepared for the Corporation for Manufacturing Excellence (Manex) and by University of California, Berkeley laboratory for manufacturing and sustainability, 1-59

Smolders E, Degryse F (2002) Fate and effect of zinc from tire debris in soil. Environ Sci Technol 36:3706-3710

Suslick KS, Doktycz SJ (1989) The sonochemistry of Zn powder. J Am Chem Soc 111:2342-2344

Van Rooij JGM, Jongeneelen FJ (2010) Hydroxypyrene in urine of football players after playing on artificial sports field with tire crumb infill. Int Arch Occup Environ Health 83:105-110

Van Ulirsch G, Gleason K, Gerstenberger S, Moffett DB, Pulliam G, Ahmed T, Fagliano J (2010) Evaluating and regulating lead in synthetic turf. Environ Health Perspect 118-10:1345-1349

Verschoor AJ (2007) Leaching of zinc from rubber infill on artificial turf (football pitches). RIVM report 601774001/2007

Whitlock CEA (2008) Review of synthetic turf safety. Somerset Hills School District, New Jersey

Wik A, Dave G (2009) Occurrence and effects of tire wear particles in the environment - a critical review and an initial risk assessment. Environ Pollut 157:1-11

Zhang JJ, Han IK, Zhang L, Crain W (2008) Hazardous chemicals in synthetic turf materials and their bioaccessibility in digestive fluids. J Expo Sci Environ Epidemiol 18:600-607

Zhang SL, Xin ZX, Zhang ZX, Kim JK (2009) Characterization of the properties of thermoplastic elastomers containing waste rubber tire powder. Waste Manag 29:1480-1485 